\title{
Correction to: Clinical Applicability of an Existing Proportionality Scheme in Three-Segment Kinetic Foot Models
}

\author{
Maarten Eerdekens (iD, ${ }^{1,4}$ Filip Staes, ${ }^{1}$ Giovanni A. Matricali, ${ }^{2,3}$ and Kevin Deschamps ${ }^{1,4,5,6}$
}

${ }^{1}$ Musculoskeletal Rehabilitation Research Group, Department of Rehabilitation Sciences, KU Leuven, Tervuursevest 101, 3001 Leuven (Heverlee), Belgium; ${ }^{2}$ Department of Orthopedics, UZ Leuven, Leuven, Belgium; ${ }^{3}$ Department of Development and Regeneration, KU Leuven, Leuven, Belgium; ${ }^{4}$ Clinical Motion Analysis Laboratorium (CMAL), UZ Leuven, Pellenberg, Belgium; ${ }^{5}$ Division of Podiatry, Institut D'Enseignement, Supérieur Parnasse Deux-Alice, Brussels, Belgium; and ${ }^{6}$ Department of Podiatry, Artevelde University College, Ghent, Belgium

\section{Correction to:}

\section{Annals of Biomedical Engineering}

https://doi.org/10.1007/s10439-019-02344-8

This article was updated to correct Giovanni A. Matricali's name.

Publisher's Note Springer Nature remains neutral with regard to jurisdictional claims in published maps and institutional affiliations.

Address correspondence to Maarten Eerdekens, Musculoskeletal Rehabilitation Research Group, Department of Rehabilitation Sciences, KU Leuven, Tervuursevest 101, 3001 Leuven (Heverlee), Belgium. Electronic mail: maarten.eerdekens@uzleuven.be

The original article can be found online at https://doi.org/10. 1007/s10439-019-02344-8. 